\title{
Offender management: a review of approaches, benefits and challenges
}

\begin{abstract}
With such a high proportion of UK crime being committed by the same set of offenders, the Home Offce introduced Integrated Offender Management as a means of reducing re offending in the UK. By combining the efforts of the police force, probation services and non-statutory organizations, offenders receive a more intensive rehabilitation treatment and support regime. This review considers the approaches taken by various pioneer counties since 2009 , with a focus on the benefits and challenges realized until present. It has been found that co-locating all services, and using an established selection and de-selection process, is key to extracting the best results from the scheme. The biggest challenge still faced by IOM is offender engagement, as current statistics show that re-offending rates during and after the programme are still at unsatisfactory levels.
\end{abstract}

Volume 6 Issue 6 - 2018

Keywords: integrated offender management re-offending policing rehabilitation

\section{Andrew O'Hagan, Alexandra Elliott \\ Department of Science and Technology Nottingham Trent University, UK}

Correspondence: Andrew O'Hagan, Department of Science and Technology Nottingham Trent University, Clifton Lane, Nottingham NGI I 8NS, United Kingdom, Tel +44 I I 58483 I53, Email andrew.ohagen@ntu.ac.uk

Received: December 12, 2018 | Published: December 28, 2018

\section{Introduction}

\section{What is integrated Offender management?}

Integrated offender management (IOM) is a government strategy introduced around $2009,{ }^{1}$ to develop the co-ordination of multiple agencies handling offenders and individuals at risk of offending. ${ }^{2}$ IOM brings local agencies together from both statutory and non-criminal sectors. These often include some or all of the following organizations: the police, local authorities, national health services (NHS), probation services, prisons, youth offender services, and organizations from within the voluntary and community sector (VCS). ${ }^{3}$ However, the specific organizations and approaches that are used nationwide vary depending on the local crime trends, crime reduction priorities and the programmes or schemes available in the given area. Some of the approaches taken by the 'pilot counties' will be discussed within this review. ${ }^{1}$

\section{What is the aim of IOM?}

Although there are different approaches, all still aim to reflect the key principles outlined by Home Offce and the Ministry of Justice outlined in Figure $1 .^{4}$

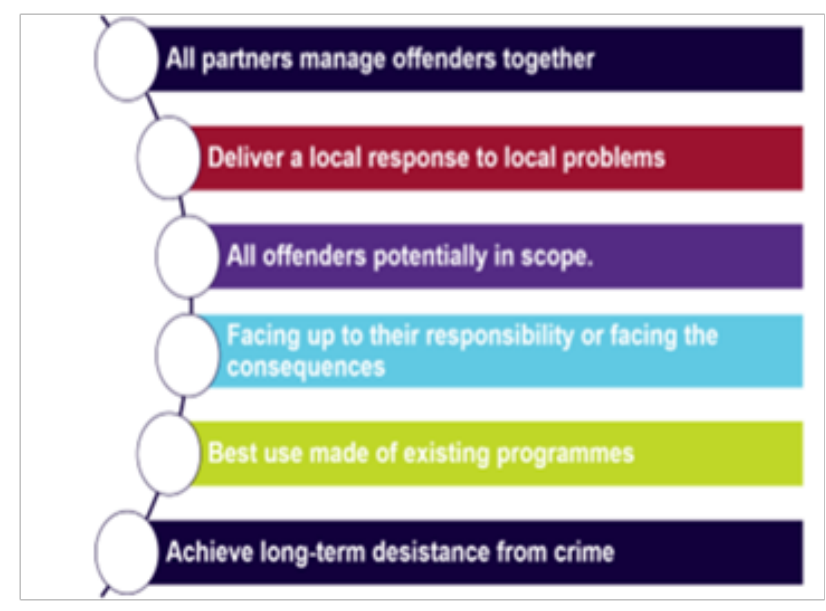

Figure I The six key principles of integrated offender management.

\section{Inter-agency management}

The success of the project relies primarily on the ability of the partner organizations to co-operate and share the relevant information seamlessly. This can be achieved firstly by ensuring that all parties involved share the same vision for the project, alongside a shared understanding of what role they each play in reaching given targets. There must also be clarity in what responsibilities are held by each body, with clear processes in place to ensure tasks are referred to the correct agencies and/or individuals.

\section{Local response}

For the most effective delivery of IOM, the response is tailored to the local crime and re-offending priorities. These priorities are proposed by local community safety partnerships, and the local Police and Crime Commissioners. This means that the issues that are prioritised not only address the crimes that are considered most prevalent or serious from a law enforcement perspective, they also address the strongest concerns of the people within the community. Another element of IOM considers what measures are put in locally to ensure victims are provided with the correct support. By listening and acting on the needs of the victims at various points within an investigation, the organizations can improve their support networks and feedback outcomes into the agenda. Although the views of the locals are important to the success of the scheme, it is important to not lose sight of other factors such as cross-border crime, and national crime targets

\section{Collation of information}

The collation of information is essential for IOM to function smoothly. Information on all offenders: regardless of age, gender, religion, or ethnicity, should be available to all agencies to organise resources and assign offenders the correct support. This reduces the risk of offenders slipping through the cracks, and subsequently not being provided with suffcient support. There is also less risk of duplication of effort, time, and resources from multiple organizations to the same offender. The level of management of an individual will vary depending on the severity of the risk they could pose to the community and the risk of re-offending. By combining knowledge from all organizations, prolific offenders that are continually offending 
are identified to all as high risk. The offenders with the highest severity and risk are then prioritised.

\section{Rehabilitation}

It is generally known that the more support an offender has, the lower the risk of re-offending. Through IOM, offenders are offered support even if they are not subject to probation orders by the courts. This help is provided to ensure prioritised offenders have access to support rapidly and that it is appropriate to the individual. These support arrangements ideally, should be provided by one individual from any of the organizations within the inter-agency team. It is important to develop local standards and procedures, to provide consistent approaches and rehabilitation aims. Rehabilitation objectives, and the likely consequences of a lack of engagement from offenders who opt to participate, should be clear. The progress towards aims and the engagement of the offenders is monitored throughout to ensure engagement is of a satisfactory standard and the aims for the individual remain relevant.

\section{Existing programmes}

Depending on the county and area being considered, there are varying programmes and schemes for a range of tasks including: management of offenders, preventing re-offending, and reduction of crime. Approaches can even vary within these categories, for example approaching more specific problems such as tackling racial abuse and victimization. IOM can enhance and back-up schemes already in place such as:

\section{Drug Interventions Programme (DIP) \\ II. Prolific and other Priority Offender (PPO) \\ III. Multi-Agency Public Protection Arrangements (MAPPA)}

Each of these programmes are responsible for dealing with different types of offender, covering a range of criminal activities, each of varying severity. IOM does not replace these schemes, it acts as a framework to combine the resources and effort from all agencies to obtain the best support and responses for both the offender and the community. ${ }^{1}$ The framework provided by IOM also helps to ensure that programmes are used to the greatest effect. The joint approach enables all offenders and victims to have easier access to programmes relevant to them, which previously they may have either not known about, or had not had access to.

\section{Long term Effect}

By focusing on the individuals, IOM manages offenders in a more effcient, coordinated, and coherent manner. Even after the offcial supervision stage for an offender has been completed, support can still be provided when the individual is deemed to be at risk of reoffending and turning back to crime. This continued support is part of 'exit strategies', which aim to ensure the at risk offender remains prioritised until they have gained the required level of support to disrupt their cycle of criminal activity, preventing the individual from re-offending. ${ }^{1,2}$ This is an important disruption to make as in 2001 it was shown that $50 \%$ of crimes committed, are by the same $10 \%$ of offenders. ${ }^{5}$ Re-offending is a therefore a major issue in the UK.

\section{Discussion}

\section{National implementations}

The UK government funded a pioneering IOM scheme in 2009 at six locations across England: West Midlands, Nottinghamshire, Avon and Somerset, Lancashire, West Yorkshire and London. The funding awarded to each region was not the same amount. Of the five regions outside London, West Yorkshire received the largest amount of $£ 945 \mathrm{k}$, whilst Nottinghamshire and Avon and Somerset were only funded $£ 50 \mathrm{k}$ for the two-year pioneering scheme. Nottinghamshire gained additional funding for the IOM scheme from local Community Safety Partnerships (CSP's), National Offender Management Service (NOMS), the European social fund and more. ${ }^{2}$ Each region was responsible for the delegation of its own funds and resources, resulting in a range of approaches being developed across the country. The priorities of each area were greatly influenced by their respective CSP's. Some counties developed or extended their use of PPO, DIP and MAPPA programmes already in place to create a more organized management. Therefore, to fully understand the IOM process these three schemes must be outlined.

\section{PPO}

The Prolific and Other Priority Offender (PPO) scheme began in September $2004^{6,7}$ replacing the persistent offender scheme. ${ }^{8}$ As the name suggests PPO focuses on offenders stuck in the cycle of re-offending, and potentially causing continuing problems in their communities. The PPO programme is overseen by Crime and Disorder Reduction Partnerships (CDRP's) and is run by multiple agencies (Police, Prison Service, Probation Services, and the CPS) which are co-ordinated by the Local Criminal justice board (LCJB). Offenders in the programme are managed by three core approaches 'Catch and Convict', 'Rehabilitate and Resettle' and 'Prevent and Deter'.' Each offender is considered individually to provide the appropriate responses; it is considered a high intensity scheme, with frequent contact and supervision by offender managers and local authorities. The 'Catch and Convict' and 'Rehabilitate and Resettle' approaches focus on offenders. These offenders can be well known to the relevant agencies or community and have a high risk of returning to crime. By being proactive with these approaches, monitoring engagement and behaviors, it is thought that there could be a reduction in re-offending when the appropriate support and opportunities are available, to allow the offender to break the cycle. Depending on the frequency of the offenders re-offending and co-operation of the offender with the program, approaches can alter. The 'Prevent and Deter' approach educates the community, particularly young people, of the effects that offending can have on your life, with the hope of reducing the potential numbers of young people becoming prolific long-term offenders.

\section{DIP}

DIP (Drug intervention Programme) was launched in 2003, and was funded by the public to combat individuals turning to crime to feed their drug additions. ${ }^{10,11}$ The scheme works primarily with adult offenders using heroin and cocaine (Class A drug addicts). It was an innovative scheme, as it was the first globally to combine agency efforts, aiming to ensure that this 'type' of offender gained access to the right treatment and support for their addictions. ${ }^{11}$ Like PPO, DIP is a multi-agency programme with services tailored specifically to meet the needs of each offender. The scheme provides support, and assists addicts throughout the justice system process, from when they are arrested, throughout custody, during sentencing and upon release. DIP identifies drug misusers by testing for the Class a Drug; Heroin, Cocaine, Crack Cocaine and opiates at the point of arrest for trigger offences. Trigger offences include: drug possession, drug possession 
with intent to supply and acquisitive crimes such as burglary, robbery and theft once identified the offender can be required to be assessed for treatment and or support, in accordance with the new police power proved by the Drugs Act 2004. The assessment process aims to determine the individuals' dependency to the drug, and their future tendencies for further misuse. Depending on the outcome of initial assessments, extended assessments and/or treatment can be arranged. It is important to note that further treatment is optional; UK law does not require the offenders to engage with this course of action at the point of arrest. In some cases, however, this treatment plan can be put in place as a condition to bail. Referral by the criminal justice integrated teams (CJIT) is now the second largest route to treatment for classes a drug user. ${ }^{12}$ The CJIT act as coordinators, providing individual case management, specialised to each specific offender. This links the offender to the right scheme or organization for their needs. Using a personalised approach ensures individuals are provided with the right care, and the correct support at the conclusion of their treatment, allowing them to move forward and not fall through the cracks, back into a pattern of drug misuse and/or re-offending. ${ }^{13}$

\section{MAPPA}

MAPPA was introduce in $2000,{ }^{14}$ originally in the Criminal Justice and Court Services Act, then in the Criminal Justice Act 2000, sections $325-32,{ }^{15}$ to set out guidelines on how offenders involved in serious sexual or violent offences, should be monitored and managed as to not pose a threat to their local community. MAPPA's lead organizations include the police force, prison service and local probation department; however, many other agencies help to manage offenders with MAPPA arrangements to improve the individuals' situation. For instance, helping with finding employment, housing, or providing the individual with opportunities to improve their education, and in doing so, their job prospects. Offenders are referred to MAPPA arrangements for management, at the point of identification, i.e. when they are convicted, sentenced, or cautioned for a relevant crime. This is passed on to the relevant MAPPA organizations to be aware of offenders who may pose a risk and prepare for their release and/or organise their community probation orders. Management of offenders with MAPPA arrangement is levelled depending on the offence and sentencing of the offender. Within MAPPA the offenders are ranked level 1-3, where level 1 represents a standard level of offender management within one organization, level 2 requires inter-agency involvement and therefore MAPP meetings are required, and level 3 offenders (for the offenders who have committed the most severe offences) which require senior members from each participating organization to be present at MAPP meetings. Most offenders under MAPPA are deemed level 1 and 2. Alongside using and developing existing schemes, funds were used in other ways to help manage offenders more effciently. West Midlands used funds to develop a data management system improving IT resources, whilst Lancashire financed the assignment of staff from all organizations to their joint IOM headquarters. ${ }^{2}$ The approaches taken by each county or police jurisdiction varied not just in terms of use of resources, but also the scale to which they would implement them. West Yorkshire ran the scheme county wide, in contrast to the other pioneer areas. Lancashire and West Midlands started implementation within specific local authorities (LA's), whilst Avon and Somerset focused on Bristol, and Nottinghamshire started with Nottingham City before expanding further down the line (discussed below). A more recent review of IOM was carried out by HM Inspectorate of Probation and HM Inspectorate of Constabulary in 2014. It considered IOM approaches used in Bournemouth, Conwy, Leeds, Norwich, Tame side and Waltham Forest. ${ }^{8}$ In these areas the IOM was highly dependent on the dedication of the heads of police and probation services, all six areas used police force representatives as 'lead operational manager', however, a "strong probation input" in the strategic approaches for the local areas was seen in only three regions. ${ }^{8}$ Two areas, which were not specifically named within this review, had a poorly developed IOM scheme. After 9 months of implementing the pilot, they were still struggling to adjust, and find effective inter-agency partnerships. Staff in probation services were out of the loop in the case of some of the offenders who were assigned to the IOM scheme. Therefore, the offenders were getting no additional support or services; this indicated clear communication problems between agencies. All areas had developed positive VCS relationships to provide the best possible assistance to offenders, however again in two areas this was poor. A new issue regarding staffng became apparent in this review, as in some of the areas; the number of staff dedicated to IOM was not large enough to ensure a coherent service to the offenders and to achieve IOM's true purpose, reducing re-offending. In addition to this it was said by one of the Detective Superintendents involved with the scheme that "part of the success of our team is getting the right people doing the job". ${ }^{8}$ The best teams will be comprised of individuals committed to working beyond their specific job role, to provide the optimum outcome, in line with the IOM vision. Because of such a wide variety of strategies undertaken by each area, the pioneer period established no conclusive approach for IOM to be used country-wide. However, there are clear principles that can be taken away in reference to best practice Figure 2. ${ }^{2}$ During the offender selection process, there is a need for unbiased criteria to ensure the correct offenders are allocated to the IOM approach. To aid this, all agencies should contribute to the selection model and receive all relevant information on each offender case, to make a well-informed decision. Once selected, each offender is assessed to match them to the most suitable and beneficial support available. This is made easier by collating all the information regarding agencies and services involved in IOM in each local area, allowing organizations to be fully aware of all resources and schemes at their disposal. When it is known which scheme/approach is being used in each offender's case, a care plan is drawn up, which makes clear the individual's case manager, their designated support pathway and lead organization for the offender. In all cases police provide information relating to the offender and take on the enforcement and disruption role. Once the offenders' intervention pathway is put into action, the case manager communicates and co-ordinates the interagency communications in relation to the offender. Both planned and random home visits are carried out by the offender manager, police, or probation, to assess whether the offender is adhering to the conditions set out in their care plan and showing engagement at a level deemed acceptable by those carrying out the assessment. Progress on each offenders' case is reviewed at multi-agency review meetings, engagement and interventions are discussed. When the offender is not deemed to be engaging suffciently, the review team adjust the strategies used to manage the offender from 'rehabilitate and resettl' back to the more traditional 'catch and convict' models. This could include an increase in the frequency of home visits and interventions to the offender, to help reduce the risk of re-offending. An individuals' review meeting frequency is determined by their risk and engagement in their programme. An individuals' deselection from IOM is just as important as their selection, as is the equal involvement of all organizations handling the offender in making the decision. Police involved in the pioneer areas, stated that deselection is crucial in "keeping the focus on a cohort of people who are actually active 
and who we can actually work with". ${ }^{2}$ In short, deselection of an offender is considered when they have completed their programme or received all support and benefits available to them through IOM.
Exit interviews for each offender are carried out which focus on the progress the offender has made, reflect on the challenges encountered, and highlight the changes in the offender's behaviour and lifestyle.

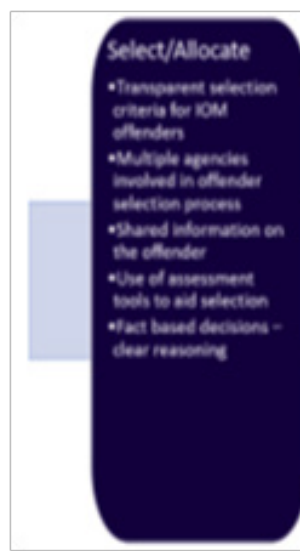

Figure 2 Best practice principles of IOM.

\section{Nottinghamshire's IOM}

Nottinghamshire's pioneer site focused on the city of Nottingham itself. The IOM approaches used, built on the PPO, DIP and General Offender Management (GOM) schemes already present in Nottingham, and dealt closely with offenders involved in serious acquisitive offences. Offences classed as acquisitive include: theft, theft of a vehicle or from a vehicle, domestic burglary, and robbery. In Nottingham the agencies involved in providing IOM included Nottinghamshire Police, social services, local housing providers, probation teams, the Job Centre, drug and alcohol rehabilitation centres and NHS mental health teams. The approaches and interventions used by these organizations were not novel, however this new scheme allowed the organizations involved to increase their resources, and in doing so, the number of offenders offered treatment and interventions. The IOM approach here had its own 'basic etho', to communicate directly to the relevant offenders the simple ultimatum of their situation, they could accept the treatment and support that was being offered under IOM, or they would instead be placed in custody for their crimes. ${ }^{2}$ This ethos was of particular importance when working with non-statutory offenders (NSO's). NSO's are offenders that are not required by law to participate in any probationary or management programmes, this typically includes individuals who had short (less than 12 months) custodial sentences, and offenders reaching the end of community orders, who need further support. However, the introduction of IOM in Nottingham allowed for the interventions and treatments to be offered as an option to NSO's. These interventions included actions from both the police force and other agencies involved in IOM. The police force and offender managers had the option to carry out multiple random home visits, collect and document information relating to the offender and their movements, which depending on the individual may or may not include electronic tagging, and increase the occurrence of neighbourhood policing in the offenders' local area. Alongside these activities, local agencies assisted the offenders to help break their cycle of re-offending. These agencies provided the support that statutory offenders are provided with, from case managers in the probation service. NSO's were informed of the scheme by letter, detailing what police actions would be taken, and the commitments and engagement required of them should they wish to participate in IOM. ${ }^{2,16}$ At the time of IOM's implementation, there was no local hub or shared building set up in Nottinghamshire from which GOM could operate. As a result, a police station had to be used, with a setup within to allow members from VCS organizations to speak with offenders when necessary. In the city of Nottingham specifically, this was not the case. The GOM had no form of co-location and was still developing links with organizations within the VCS. In more recent times Nottinghamshire IOM has expanded its scope in terms of the offenders it considers for selection, and now also includes those who are "risk of high harm", for instance individuals with domestic violence and abuse charges. ${ }^{17}$ The new Nottinghamshire Police force structure, announced on the 3rd of April 2018, has two separate geographic policing areas, City region and County region, with dedicated area commanders now managing IOM, neighborhood policing and more in both the strategic and operations departments, as shown in Figure 3, Figure $4^{18} \&$ Figure $5 .{ }^{19}$

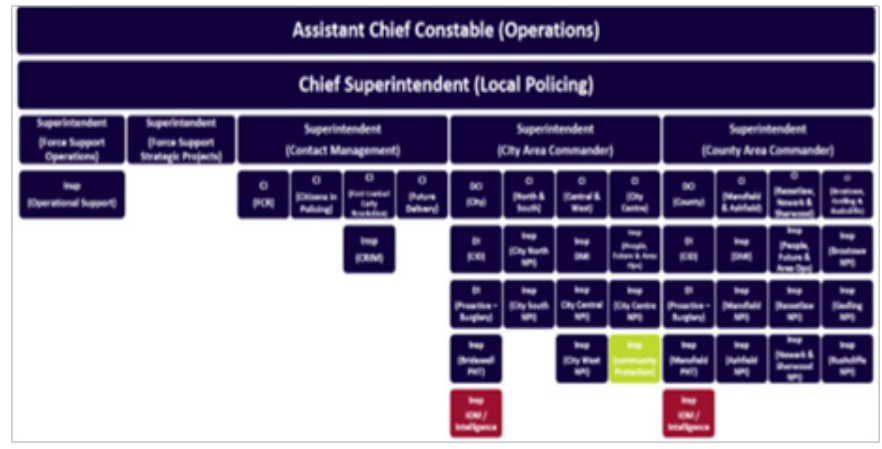

Figure 3 Nottinghamshire Police Local Policing 2018 Restructure New IOM roles indicated in red.

\section{Evaluation}

Since its conception in 2008, there have been numerous benefits and problems in the implementation of IOM. The effectiveness of the programme has been diffcult to assess, as there is very little information directly linked to IOM available, and the numbers that are available do not give a broad enough representation to draw conclusion from. For example, Table 1 shows the re-offending statistics for 65 offenders involved in the IOM inspection carried out in $2014,{ }^{8}$ however this fails to capture two key pieces of information, 
first the changes in the frequency of re-offending, and second, differentiating between those who re-offended during the IOM programme and those who committed offences after completion. The issue regarding frequency of reoffence is important as it may relate strongly to the previously mentioned statistic regarding the same $10 \%$ of offenders committing half of all offences. If these are the offenders that saw the greatest improvements, then this would result in a huge decline in total offences. The second matter of whether reoffending occurred during or after the IOM process, is key information to those running the scheme, as if the majority of offences are committed after deselection, this indicates a problem with this stage specifically, and that the offender simply wasn't ready to be de-selected, whereas offences committed during the scheme show that the problem lies more with the willingness of the offender. Figure 5 shows the total drug offences for England and Wales from 2003-2015. Although no conclusions can be drawn from one chart alone, it is interesting to note that drug crime was on a continual rise leading up to 2008 , and that since the introduction of IOM, it has shown consistent reductions year on year. This may be an indicator that IOM is particularly well suited to addressing offenders at a high risk of drug abuse and subsequent re-offending, as the early detection, alongside an increased level of support and treatment options, may have contributed to such results Table $1 .{ }^{8}$ However, these results have not happened without some significant issues being picked up along the way. The various problems can be broken into

\section{Engagement \\ II. Logistics \\ III. Communication \\ IV. Location}

\begin{tabular}{|c|c|c|c|c|c|c|c|c|}
\hline \multicolumn{9}{|c|}{ Assistant Chief Constable - Operations } \\
\hline \multicolumn{9}{|c|}{ Detective Chief Superintendent - Crime } \\
\hline \multicolumn{3}{|c|}{ 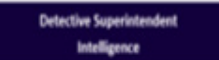 } & \multicolumn{3}{|c|}{ 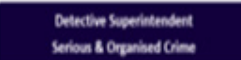 } & \multicolumn{3}{|c|}{ 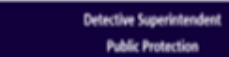 } \\
\hline$=$ & $=$ & $m$ & $=$ & $\lim _{\infty \rightarrow \infty}^{\infty}$ & - & $\infty$ & $\infty$ & 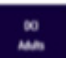 \\
\hline . & & & $\therefore$ & $\Delta$ & $\sin$ & $\ddot{z}$ & 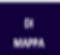 & $\therefore$ \\
\hline 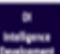 & & & & 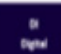 & 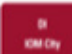 & س. & $=\infty$ & $\therefore$ \\
\hline 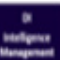 & & & & \pm & & & & 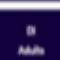 \\
\hline
\end{tabular}

Figure 4 Nottinghamshire police crime department 2018 Restructure. New IOM roles indicated in red.

Table I Re-offending statistics for a sample of 65 offenders involved in the joint inspection of the IOM approach from $2014^{8}$

\begin{tabular}{lll}
\hline Offending status & Number & Percentage* (\%) \\
Breached conditions or re-offended & 40 & 62 \\
Programme completed: No re-offending & 9 & 14 \\
Programme ongoing: No re-offending & 16 & 25 \\
\hline
\end{tabular}

\section{Engagement}

One of the first challenges faced when setting up an IOM team, is gaining the support of organizations within the VCS. This involves support of not just the key principles of IOM, but also a commitment from all agencies, to cooperate fully and uncompromisingly with the other agencies. The initial issue with engaging the VCS was what was being requested of the workers at the various organizations. The large amount of additional responsibility associated with IOM, as well as the training involved to undertake an offender manager role, may have seemed daunting in the timescale that was suggested for the pilot scheme. ${ }^{20}$ Once these roles had been established, it was important to develop trust between the VCS and statutory bodies. This proved to be diffcult, particularly in the case of police offcers, where their previous offender management approach was based on a 'catch and convict' model. This is in stark contrast to the 'rehabilitate and resettle' mindset, adopted by IOM from the probation services within the PPO scheme. To combat this and help soften the transition of role for the police offcers involved in IOM (designated offcers, neighborhood police offcers and beat offcers), four 'new roles' were developed which were: intelligence gathering, pathways support, enforcement, and disruption/attrition. ${ }^{2}$ These roles helped guide offcers in their approaches and gave a clearer idea of which collaborating organization they needed to communicate with in a given situation. Through this there was a change in attitude among the majority of offenders towards the police. Prof. Paul Senior suggests this improved relationship is down to increased trust in the police, and can be seen in this offenders response to the police's involvement in IOM, "Instead of having police coming and saying you're arrested or throwing you in jail and roughing you up, its coming and they're trying to help you and I think that makes a big difference in people's lives". ${ }^{2}$ However, there were a small proportion of offenders who still held a more negative view of the police, one such offender said, "I've had bad experiences in the past and I just don't want them knocking on my door because this is the hard thing, you've got a police offcer come round to your house who's locked you up in the past, smashed your door down while your kids are in bed, ransacked your house, put you in front of court then a couple of years down the line that police offcers knocking on your door, coming into your house 'hello how you doing?' Why would you want that person in your house after they'd done all that to you $?^{2}$ In the joint review by the Inspectorate of Probation and the Inspectorate of Constabulary, only $12.5 \%$ offenders who participated in IOM, saw the police involvement as a negative aspect. $^{8}$

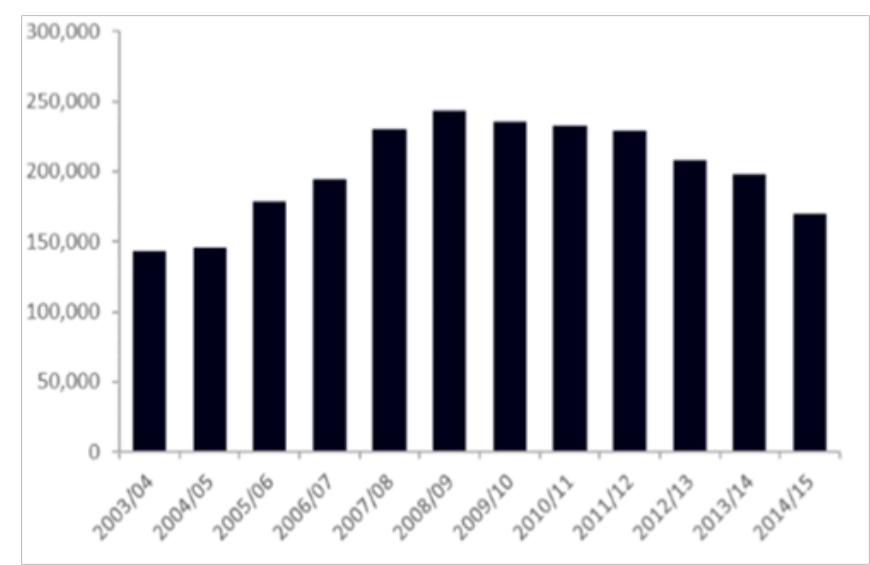

Figure 5 Total drug Offences between 2003-2015. ${ }^{19}$

\section{Logistics}

After gaining the support of the agencies to participate in IOM, an approach had to be developed that was sustainable, and in the 
interests of all parties involved. This presents diffculties of its own, as each agency has its own agenda and priorities when considering offenders. The police and probation service were often considered the 'lead professionals'. In addition to this, there is an increased demand on services and resources, as a consequence of more offenders being recommended for support. This is purely a symptom of less offenders 'slipping through cracks' as mentioned earlier. This strain would have been exacerbated by the large financial cuts to services around the time of IOM's first implementation.

\section{Communication}

Perhaps the biggest challenge of IOM was developing a clear communication pathway between all the organizations involved, where all agencies had an equal say. Each organization involved in IOM, was committed to improving their overall community safety and offender management in their local areas, however, all organizations had differing opinions as to what type of offending or class of offender was the most problematic. In the pioneer sites this was demonstrated, a police representative stated "7 CSPs in a city want 8 different things... if we give control to the CSP, we will have eight separate models". 2 In other words, these differing priorities would influence the kind of IOM approach that the various organizations would want to take. It was therefore crucial that all agencies communicated effectively to find a unified approach that took into consideration all types of offender and worked for the entire county.

\section{Location}

In the early stages of IOM implementation, many regions did not have co-located bases for their IOM teams. Nottinghamshire, Lancashire, and Somerset and Avon's IOM were based within a police station or police-controlled building. It was felt by VCS organizations that having a police station base for IOM was detrimental to offender engagement, as many of these offenders may have negative associations to the police stations they were expected to go to for help and support. Having IOM based in a police station also impacts staff from the other agencies, as to have access to the building they had o be vetted. If this was not cleared in a timely manner, the individual could face diffculty entering the facility, and would therefore be unable to carry out their role in situ. As the scheme progressed, some counties did move towards a co-located model, the benefits of which are outlined in Figure 6 below. It is shown that co-locating the IOM team; police, probation services, VCS and more, under one roof helps to co-ordinate interventions in a more effcient, straight-forward, and cost-effective manner. Because all organizations are present, they can discuss cases and updates of an individual's progress when necessary, minimising the endless cycle of emails and phone calls when attempting to track down colleagues from partner agencies the benefits shown above fall into two clear categories; those that affect the members of the IOM team, and those that enhance the support for the offender. The team's ability to carry out their role is improved because of simpler, more fluid communication and information sharing. The support for offenders is improved through a neutral choice of location that houses all the participating agencies. When these criteria are met, trust can be developed between the offenders and those trying to help them. Moving the centres away from police stations makes for a safer environment in their eyes, where less negative connotations are held. There is also an economic benefit of a joint base, the funding and resources needed to accommodate the organizations is reduced compared to when they each have individual running costs at separate locations. This results in increased available funds to be put towards combating offending.

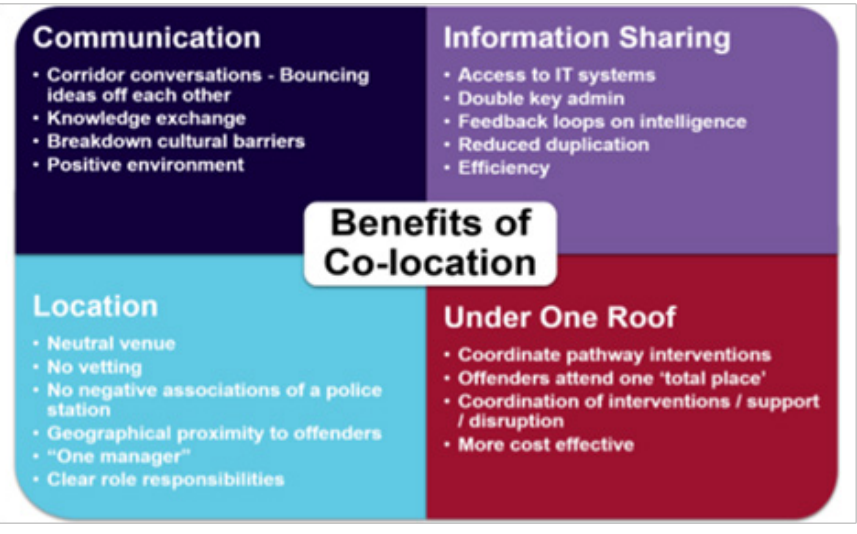

Figure 6 Benefits of co-location.

\section{Conclusion}

In summary, the aim of any IOM implementation should follow the six key principles outlined by Home Offce; inter-agency management of offenders, a local response to local problems, collation of information to have 'all' offenders in scope, rehabilitation, best use of existing programmes and to achieve a long-term desistance from crime. This is accomplished through the use of pre-existing programmes, although the schemes used are dependent on the county in question. In general, the programmes used in most regions where IOM has been implemented include PPO, DIP and MAPPA, all of which already contain elements of multi-agency involvement, providing a good foundation from which IOM is built. The pioneer scheme launched in 2009 produced a multitude of approaches, as a result of each county being responsible for the delegation of its own funding. For example, West Midlands prioritised the improvement of communication between the agencies, and therefore developed new data management systems, whereas Lancashire saw co-location as a greater priority and as a result, funded the movement of services and staff into a joint base. Disparity among the counties, led to an un-organized system that lacked clarity in terms of the role of each organization. This required the introduction of best practice principles, proposed by Prof. Paul Senior as part of the Home Offce and Ministry of Justice evaluation, which highlighted the importance of transparency and integration, by breaking the IOM process into five clear stages; selection, planning, implementation, review, and evaluation. In doing this, the process and the roles of each organization were made clearer. Although there is little data available to consider the effectiveness of the IOM approach nationwide, it has been inferred that IOM may be of particular benefit to offenders with drug abuse and misuse problems. The overall impact of IOM can't be measured directly as it is seen to change depending on assessment criteria and the region under evaluation. It is important to consider not just re-offending or breaches of conditions while under IOM management, but also possible reductions in the frequency of re-offending, as this still shows progress in relation to each specific offender. In other words, poor statistics relating to improvements in re-offending rates, do not translate directly to overall crime reductions, as each individual will experience various levels of rehabilitation. Over a longer time period, statistics relating to IOM will begin to shed more light on areas that need improvement. From the evaluation given in this review, some improvements can be suggested. Engagement 
of offenders may need to be analysed, as although the majority of offenders see IOM as a positive programme, the re-offence rates whilst on the programme may suggest otherwise. In addition to this, the negative views from some offenders to the involvement of police offcers in the 'rehabilitation and resettle' component of IOM, could be a result of offenders not fully accepting responsibility and moving forward on the path of desistance. Effort must also be made by organizations involved, to sustain a positive relationship with the VCS agencies and partners, most importantly in the initial training phase where volunteers reservations in joining the IOM team would be most prominent. Logistically, the running of the scheme will have naturally improved in recent years as new staff and offcers have IOM built into their training, and most IOM teams have now got co-located bases to optimise the many benefits discussed in this review. This combined with the introduction of the best practice principles will had led to a more fluid, better understood system. However this does not address the issue of each agency having its own priorities, and an effort should be made to ensure that all organizations maintain an equal voice, especially during stages such as de-selection, which appears to be a weak point in the system according to the findings thus far. Another important element is the dynamic nature of crime patterns. Local priorities may change over time and in some cases the VCS and other non-statutory organizations may have a clearer view of these local issues than statutory organizations, accentuating the need to listen to the input from a variety of institutions. This ties in closely with the issue of communication, as the pathway for transfer of information may be the determining factor in how effciently and accurately knowledge is shared. IOM still has a way to go before it is seen as standard practice, however I believe that with continued effort from all agencies involved, it has the potential in the coming years, to effectively tackle the issue of re-offending.

\section{Acknowledgments}

I would like to thank the Anko Lange of the Dutch National Police together with Steven Edwards and Francois Kloosterhuis of Assen City Hall, for fueling my interest in this field of work.

\section{Conflicts of interest}

The author declares that there are no conflicts of interest.

\section{References}

1. Lane B, Kangulec S. Integrated offender management workforce development ProQuest Criminal Justice - ProQuest. Safer Communities. 2012;11(3):154-158.

2. Senior P, Wong K, Culshaw A, et al. Process Evaluation of Five Integrated Offender Management Pioneer Areas. 2011.
3. MAPPA. Integrated Offender Management (IOM). 2018.

4. Home Offce. Ministry of Justice. Integrated Offender Management Key Principles. 2015.

5. Home Department. Criminal justice: The way ahead. 2001.

6. Home Offce. Prolific and other priority offender program five years on: Maximising the impact. 2009.

7. Hopkins M, Wickson J. Targeting prolific and other priority offenders and promoting pathways to desistance: Some reflections on the PPO programme using a theory of change framework. Criminology and Criminal Justice. 2013;13(5):594-614.

8. HM Inspectorate of Probation, HM Inspectorate of Constabulary. A Joint Inspection of the Integrated Offender Management Approach. 2014.

9. Geddes L. In Search of Collaborative Public Management: The prolific and other priority offender programme. Public Management Review. 2012;14(7):947-966.

10. Home Offce. Drug Intervention Programme Operational Handbook. 2011.

11. Home Offce. Drug interventions programme. Conditional cautioning and the dip condition: Operational Guidelines for Criminal Justice Integrated Teams and Partners. 2008.

12. Osborne A. Future delivery of the Drug Interventions Programme: Do the benefits justify the costs? Journal of Forensic and Legal Medicine. 2013;20(7):816-820.

13. Skodbo $\mathrm{S}$, Brown $\mathrm{G}$, Deacon $\mathrm{S}$, et al. The Drug Interventions Programme (DIP): addressing drug use and offending through 'Tough Choices'. Home Offce; 2007.

14. Henson T, Riordan SA. MAPPA and detained patients: Views from professionals about referral. Journal of Forensic Psychiatry and Psychology. 2012;23(4):421-434.

15. Ministry of Justice-National Offender Management Service. MAPPA Guidance 2012. 2012.

16. Home Offce. Ministry of Justice. Integrated offender management government policy statement. 2009.

17. Nottinghamshire Police. Working together for a safer Nottinghamshire and Nottingham. 2012

18. Nottinghamshire Police. New force structure for Nottinghamshire Police. 2018.

19. Offce for National Statistics. Recorded Crime Statistics for England and Wales 2002/03 - 2014/15. 2016.

20. Criminal Justice Board. Innovative VCS Involvement in IOM Arrangements Final Report of the Gloucestershire Pilot. 2011. 